\title{
Carbon transition efficiency and process cost in high-rate, large-area deposition of diamond films by DC arc plasma jet
}

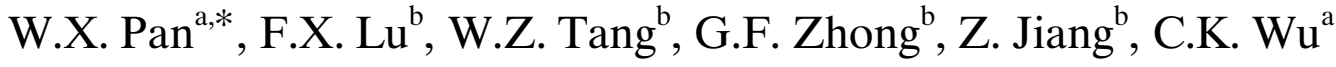 \\ anstitute of Mechanics, Chinese Academy of Sciences, Beijing 100080, PR China \\ ${ }^{\mathrm{b}}$ University of Science and Technology Beijing, Beijing 100083, PR China
}

\begin{abstract}
A new DC plasma torch in which arc jet states and deposition parameters can be regulated over a wide range has been built. It showed advantages in producing stable plasma conditions at a small gas flow rate. Plasma jets with and without magnetically rotated arcs could be generated. With straight arc jet deposition, diamond films could be formed at a rate of $39 \mu \mathrm{m} / \mathrm{h}$ on Mo substrates of $\Phi 25 \mathrm{~mm}$, and the conversion rate of carbon in $\mathrm{CH}_{4}$ to diamond was less than $3 \%$. Under magnetically rotated conditions, diamond films could be deposited uniformly in a range of $\Phi 40 \mathrm{~mm}$ at $30 \mu \mathrm{m} / \mathrm{h}$, with a quite low total gas flow rate and high carbon conversion rate of over 11\%. Mechanisms of rapid and uniform deposition of diamond films with low gas consumption and high carbon transition efficiency are discussed. (c) 2000 Elsevier Science S.A. All rights reserved.
\end{abstract}

Keywords: Diamond films; DC arc jet; Carbon conversion efficiency

\section{Introduction}

The high energy intensity and reactivity of an arc plasma generally result in a rapid processing speed for material synthesis or treatment. Diamond films can be deposited at a rate of $930 \mu \mathrm{m} / \mathrm{h}$ by the chemical vapor method in the DC arc plasma, which is the highest growth rate up to now among all methods for the diamond deposition [1,2]. Generally, DC arc plasma restricts depositions to a small area and causes a heterogeneous structure of deposited materials [2,3], because of the concentration of arc range and the steep temperature gradient in the jet. Recently, there is optimistic development on large area and uniform deposition of diamond films in DC plasma jet [4-7]. However, the high cost of the arc jet deposition process, especially the high consumption of working gases, is another critical problem, which makes it difficult to compete against other processes. Gas recycling system was introduced to reduce greatly the gas consumption of the process [6,7]. Nevertheless, problems such as gas contamination, difficulties in controlling the content and feeding position of the carbon source occurred with the recycling, besides the complication of the deposition system.

In this work, a new type of DC plasma torch was built, to achieve economically a rapid and large area deposition of high quality diamond films. Plasma conditions and deposition results were examined depending on the torch structure and working parameters. Mechanisms of the low gas consumption and high carbon transition efficiency of the process are discussed.

\section{Torch structure and process controllability}

\subsection{Geometry of arc channel and characteristics of gas flow}

High gas temperature and flow velocity is the main feature of a thermal plasma jet. Simply decreasing the

\footnotetext{
* Corresponding author. Tel.: +86-10-62554541; fax: +86-1062561284.

E-mail address: wx.pan@bj.col.com.cn (W.X. Pan).
} 
gas flow rate for generating a plasma jet will affect the arc stability or even cause serious erosion of electrodes. The new torch developed here is composed of a long narrow arc channel and a wide anode nozzle. A schematic drawing of the new DC arc plasma torch is shown in Fig. 1. The long and narrow channel makes it possible to maintain stable working conditions of a plasma jet at small gas flow rate, and the wide nozzle permits an enlargement of the jet-affected region for large area deposition of diamond films. That is, the narrow section works as a plasma stabilizing and gas velocity controlling part, and the deposition conditions could be mainly regulated within the wide nozzle. Plasma jets with and without magnetically rotated arcs could be generated by regulating the working parameters and by changing the torch nozzle of different size and geometry. A typical nozzle structure used for the generation of magnetically rotated arc jets is shown in Fig. 2.

\subsection{Effects of $\mathrm{CH}_{4}$ and $\mathrm{H}_{2}$ feeding position}

$\mathrm{CH}_{4}$ gas feeding is an important factor in DC arc plasma deposition of diamond films. It could affect the accumulation of carbon deposits at the wall of arc channel and affect the mixing of $\mathrm{CH}_{4}$ into the plasma flow. These will be related to the contamination by carbon deposits and to the transition efficiency of carbon in $\mathrm{CH}_{4}$ to diamond. Accordingly, the new torch has located gas passages (I-IV in Fig. 1) between the

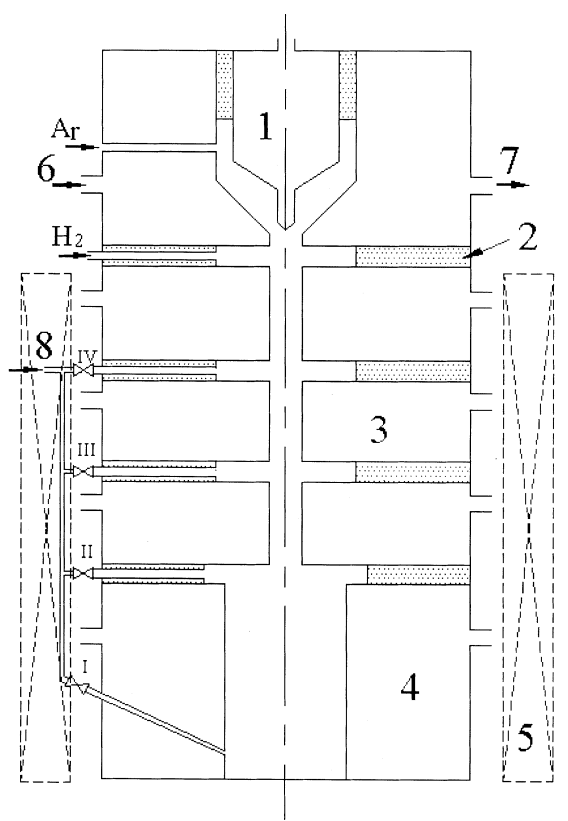

Fig. 1. Schematic drawing of the new torch. The numbering denotes: (1) cathode; (2) insulator; (3) interelectrode insert; (4) anode; (5) magnetic coil; (6) water in; (7) water out; (8) $\mathrm{CH}_{4}+\mathrm{H}_{2}$ inlet; and $\mathrm{I}-\mathrm{IV}$, for $\mathrm{CH}_{4}$ gas inlets.

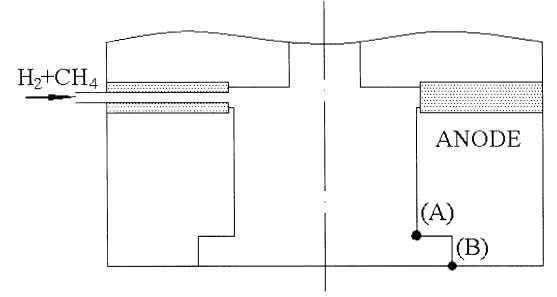

Fig. 2. Schematic diagram for the anode nozzle to generate magnetically rotated arc plasma.

constriction segments of the arc channel. These passages could be chosen as $\mathrm{CH}_{4}$ gas supply to examine the effects of $\mathrm{CH}_{4}$ feeding positions on the diamond deposition. At the same time, a large amount of hydrogen and hydrogen containing species is needed for high quality deposition of diamond films. Gas feeding of hydrogen from these passages is favorable to reduce cathode erosion of the torch.

\section{Plasma conditions and diamond deposition}

\subsection{Experimental}

A DC power supply of $30 \mathrm{~kW}$ capacity was used to generate the plasma jet at a chamber pressure of 1.6-2.6 $\times 10^{4} \mathrm{~Pa}$. The plasma working gas was a mixture of $\mathrm{Ar}, \mathrm{H}_{2}$, and $\mathrm{CH}_{4}$, with a flow rate of 5-14 $1 / \mathrm{min}, 1.6-3.51 / \mathrm{min}$ and $36-70 \mathrm{ml} / \mathrm{min}$, respectively. Plasma jets with and without magnetically rotated arcs could be generated by regulating the working conditions and changing the torch nozzle. Table 1 indicates the plasma generating and diamond deposition conditions.

Molybdenum pieces were used as the substrate for diamond deposition. Substrate temperature was measured by using an infrared pyrometer. Surface structure of deposited diamond films was observed with scanning electron microscopy (SEM). Quality of the films was assessed by Raman spectroscopy. Carbon conversion rate was estimated according to the deposition rate and area of the diamond film and the feeding rate of $\mathrm{CH}_{4}$ gas.

Table 1

Plasma generating and diamond deposition conditions

\begin{tabular}{lc}
\hline Gas flow rate $(1 / \mathrm{min})$ & \\
$\mathrm{Ar}$ & $5-14$ \\
$\mathrm{H}_{2}$ & $1.6-3.5$ \\
$\mathrm{CH}_{4}$ & $0.036-0.07$ \\
Input power $(\mathrm{kW})$ & $8.0-15$ \\
Gas pressure $\left(10^{4} \mathrm{~Pa}\right)$ & $1.6-2.6$ \\
Substrate temperature $\left({ }^{\circ} \mathrm{C}\right)$ & $910-1040$ \\
Distance $(\mathrm{mm})^{\mathrm{a}}$ & $12-100$
\end{tabular}

${ }^{\mathrm{a}}$ Distance from torch nozzle to substrate. 


\subsection{Straight arc jet}

The jet shows quite strong rigidity and favorable stability as shown in Fig. 3a generated by using an anode nozzle of small diameter, at a pressure of lower than $2.6 \times 10^{4} \mathrm{~Pa}$ and an Ar flow rate of higher than 7 $1 /$ min. External addition of the magnetic field displayed hardly any effect on the jet appearance, when the nozzle size is smaller than $\Phi 25 \mathrm{~mm}$. Simple enlargement of the nozzle size caused unstable jet conditions. And in this case, the plasma state could be relatively stabilized by moving the substrate nearer to the nozzle exit as shown in Fig. 3b. The arc core directed straightly to the substrate can be distinguished from the picture. Carbon accumulation on the arc channel wall became serious, if $\mathrm{CH}_{4}$ was fed from any of the entrance III-IV. A distance longer than $80 \mathrm{~mm}$ from $\mathrm{CH}_{4}$ entrance to substrate was needed for the diamond deposition.

Fig. 4 shows the surface morphology of diamond film deposited at $39 \mu \mathrm{m} / \mathrm{h}$ in the plasma of Fig. 3a on a Mo substrate of $\Phi 25 \mathrm{~mm}$. Heterogeneous structure and different growth condition of diamond grains appeared at the center and edge parts of the substrate. The
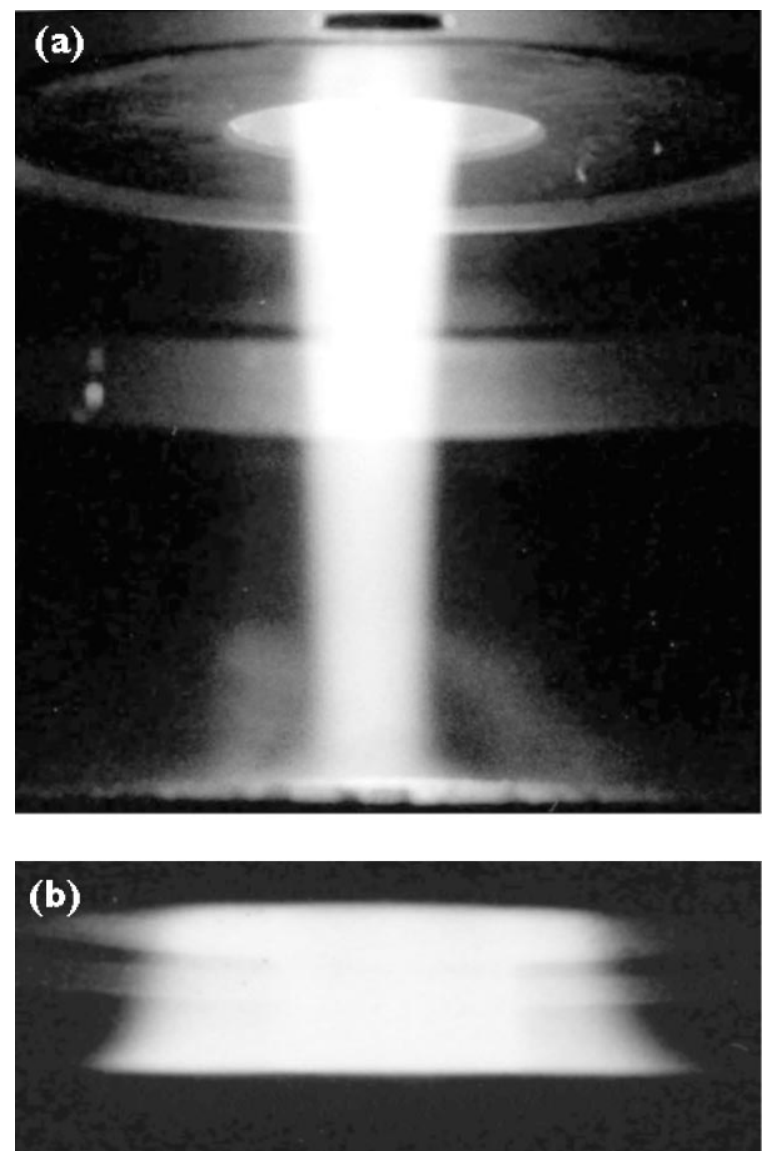

Fig. 3. Picture of the straight plasma jet generated without the effect of magnetic field: (a) with anode nozzle of small diameter; and (b) relatively lager size nozzle.

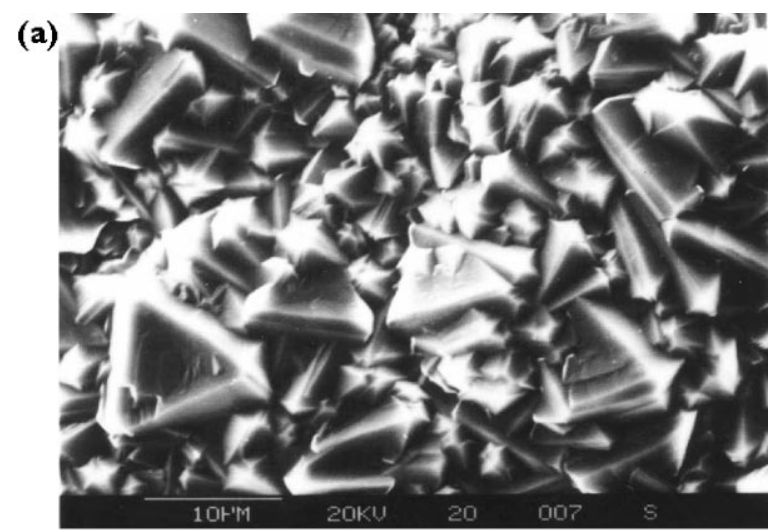

(b)

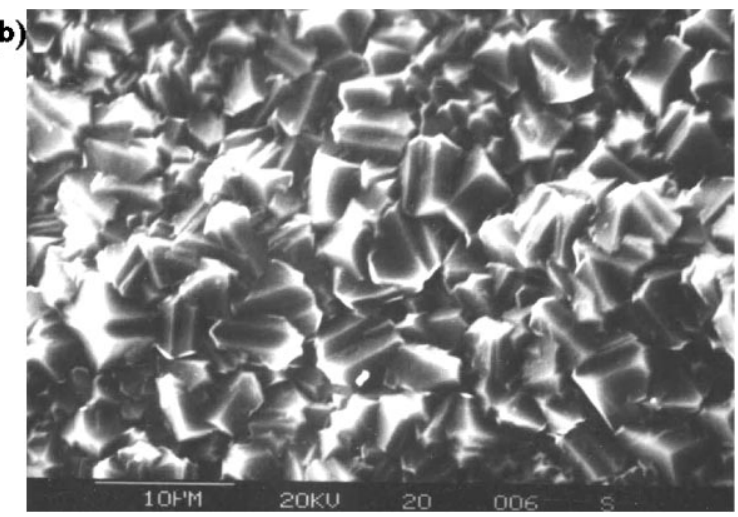

Fig. 4. Surface morphology of diamond film deposited at $39 \mu \mathrm{m} / \mathrm{h}$ in straight arc jet: (a) the center of substrate; and (b) the edge.

transition efficiency of carbon in $\mathrm{CH}_{4}$ to diamond was lower than $3 \%$. Under the plasma condition shown in Fig. 3b, diamond films less than $30 \mathrm{~mm}$ in diameter could be deposited in the arc core region.

\subsection{Magnetically rotated arc jet}

Arc jet as shown in Fig. $3 b$ could be rotated under the effect of external magnetic field, when the working pressure was higher than $2.0 \times 10^{4} \mathrm{~Pa}$ and the gas flow rate of $\mathrm{Ar}$ and $\mathrm{H}_{2}$ was lower than 8 and $2.1 \mathrm{l} / \mathrm{min}$, respectively. Intensity of the magnetic field should be increased with the increasing of gas flow rate and/or the decreasing of working pressure for rotating the arc jet. The magnetically rotating mechanism is principally the same as that described by Zhong [8]. Fig. 5a shows the plasma appearance when the arc root was rotated along the (A) circle indicated in Fig. 2. The substrate was $60 \mathrm{~mm}$ in diameter, and the plasma could not cover its surface completely in this case. Fig. $5 \mathrm{~b}$ is the picture of the plasma when arc root was magnetically rotated along the (B) circle in Fig. 2. The substrate surface of $\Phi 60 \mathrm{~mm}$ was immersed completely in the plasma. It showed great advantage in the stability of the plasma state with the low gas flow rate. Diamond deposition could occur on the whole area of $\Phi 60 \mathrm{~mm}$ at a gas flow rate of lower than $\mathrm{Ar}+\mathrm{H}_{2}=5+1.6 \mathrm{l} / \mathrm{min}$. 

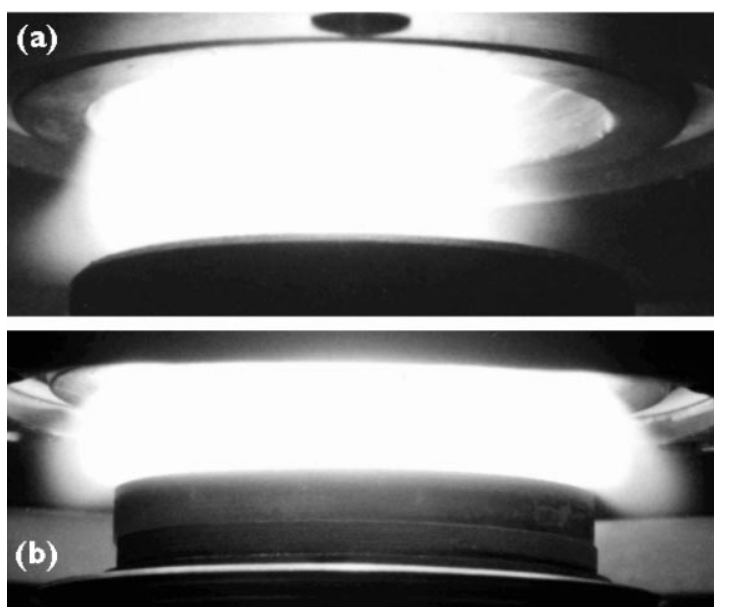

Fig. 5. Pictures of the plasma appearance: (a) the arc root was magnetically rotated along the (A) circle; and (b) rotated along the (B) circle shown in Fig. 2.

Fig. 6 shows the surface structure of diamond film deposited at $30 \mu \mathrm{m} / \mathrm{h}$ in the plasma generated at $\mathrm{Ar}+\mathrm{H}_{2}+\mathrm{CH}_{4}=5+1.7+0.036 \mathrm{l} / \mathrm{min}$. It showed a similar morphology but different grain size of the film at the substrate center and $20 \mathrm{~mm}$ from the center. Raman spectroscopy indicated a good quality of the diamond film within a $\Phi 40 \mathrm{~mm}$ region. The transition efficiency of carbon in $\mathrm{CH}_{4}$ to diamond could be higher than $11 \%$, under the deposition condition.

\section{Analysis on high carbon transition efficiency}

The homogeneous structure of deposited diamond films indicates the uniform distribution of temperature and chemical species of the plasma gas over the substrate surface. Bending the arc jet and making it rotate to scan over the substrate surface could bring about here a mixing effect of gas species and a uniform heating of the substrate. Compared with the deposition in straight jets, there was no apparent carbon accumulation on the torch wall, no matter which entrance of II-IV shown in Fig. 1 was used for $\mathrm{CH}_{4}$ feeding. This could suggest that the fed cold gas was pumped in by, and well mixed with, the rotated arc jet. The conversion rate of $11 \%$ under the magnetically rotated plasma condition is quite high, compared with the one of lower than 3\% deposited in the straight jet plasma. It is also much higher than the conversion rate of $5.7 \%$ in a gas recycle deposition of a magnetically rotated plasma [8]. Gas consumption of the rotated plasma deposition in this work is only $1 / 5$ of that of the straight jet deposition, to obtain the same amount of diamond formation. It is also much less than other magnetically rotated jet processes. These advantages could be the result of reasonable torch structure described in Section 2.1, which is sensitive to gas flow rate and makes easy control of the plasma state.
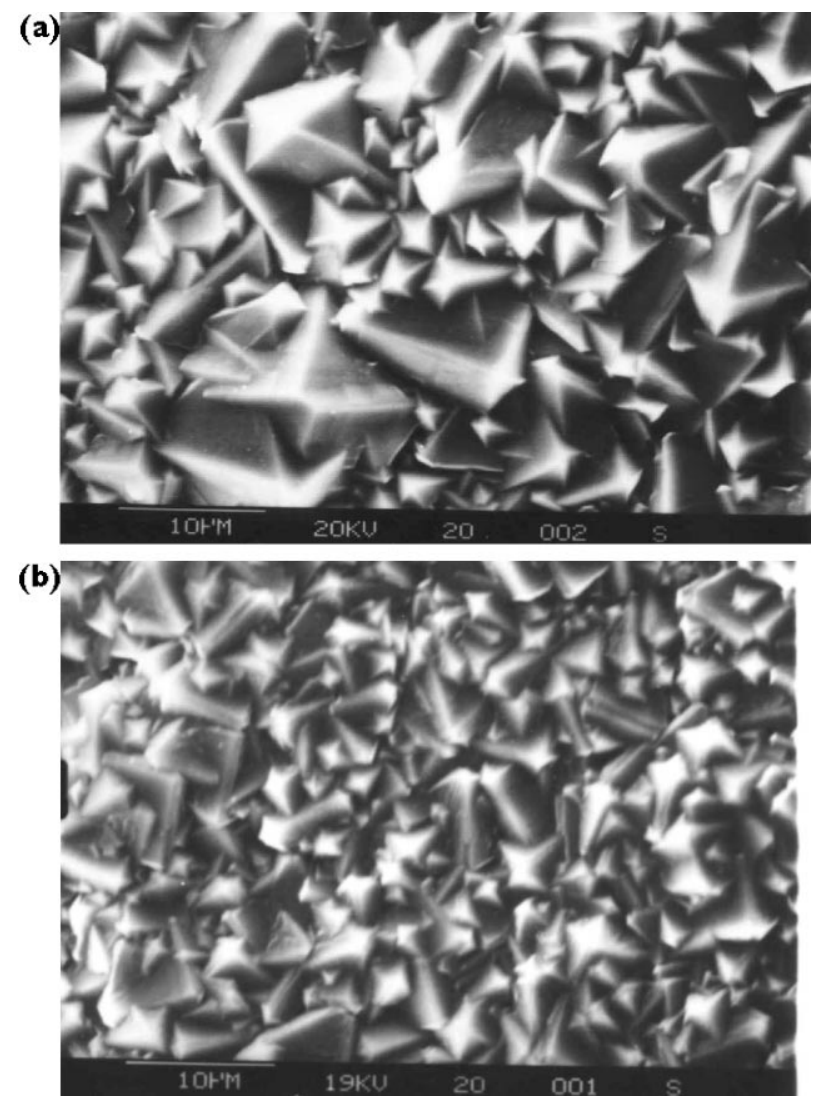

Fig. 6. Surface structure of diamond film deposited in the rotated arc jet: (a) center of the substrate; and (b) $20 \mathrm{~mm}$ away from the center.

\section{Conclusions}

The new torch showed great advantages in stabilizing plasma conditions with small gas flow rate. Plasma jets could be magnetically rotated to cover a substrate surface of $\Phi 60 \mathrm{~mm}$, when gas flow rate was lower than $\mathrm{Ar}+\mathrm{H}_{2}=8+2.1 \mathrm{l} / \mathrm{min}$. Diamond films of good quality could be deposited in an area of over $\Phi 40 \mathrm{~mm}$, and the transition efficiency of carbon in $\mathrm{CH}_{4}$ to diamond was higher than $11 \%$.

\section{Acknowledgements}

The authors would like to thank the financial support of National Advanced Materials Committee of China 863-715-Z38-03 and the key research project KJ951-120 of the Chinese Academy of Sciences.

\section{References}

[1] P.K. Bachmann, R. Messier, Chem. Eng. News 67 (20) (1989) 24. 
[2] P.K. Bachmann, in: A. Lettington, J.W. Steeds (Eds.), Thin film diamond, Chapman \& Hall, 1994, p. 43.

[3] K. Suzuki, A. Sawabe, T. Inuzuka, Jpn. J. Appl. Phys. 29 (1990) 135.

[4] Z.P. Lu, J. Heberlein, E. Stender, Plasma Chem. Plasma Proc. 12 (1) (1992) 35.

[5] A. Hirata, M. Yoshikawa, Diamond Relat. Mater. 2 (1993) 1402.
[6] F.X. Lu, G.F. Zhong, J.G. Sun et al., Diamond Relat. Mater. 7 (1998) 737.

[7] I.A. Martorell, W.D. Partlow, R.M. Young, J.J. Schreurs, H.E. Saunders, Diamond Relat. Mater. 8 (1999) 29.

[8] G.F. Zhong, Dr Thesis, University of Science and Technology Beijing, 1998. 